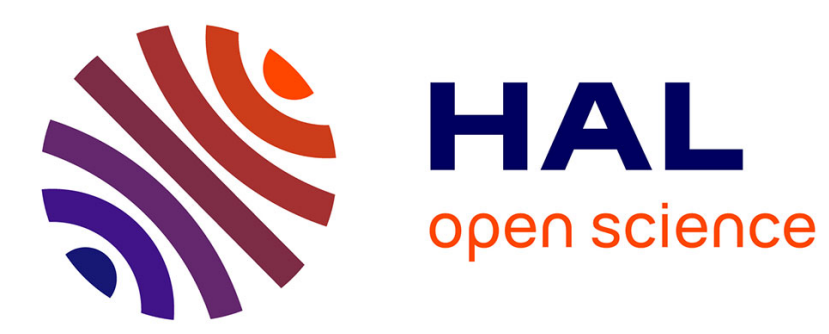

\title{
Effect of Transistor Geometry on the Electrical Characteristics of Si1-xGex Heterojunction Bipolar Transistors at Low Temperatures
}

\author{
M. Hashim, R. Lever, P. Ashburn, G. Parker
}

\section{- To cite this version:}

M. Hashim, R. Lever, P. Ashburn, G. Parker. Effect of Transistor Geometry on the Electrical Characteristics of Si1-xGex Heterojunction Bipolar Transistors at Low Temperatures. Journal de Physique IV Proceedings, 1996, 06 (C3), pp.C3-119-C3-124. 10.1051/jp4:1996318 . jpa-00254236

\section{HAL Id: jpa-00254236 https://hal.science/jpa-00254236}

Submitted on 1 Jan 1996

HAL is a multi-disciplinary open access archive for the deposit and dissemination of scientific research documents, whether they are published or not. The documents may come from teaching and research institutions in France or abroad, or from public or private research centers.
L'archive ouverte pluridisciplinaire HAL, est destinée au dépôt et à la diffusion de documents scientifiques de niveau recherche, publiés ou non, émanant des établissements d'enseignement et de recherche français ou étrangers, des laboratoires publics ou privés. 


\title{
Effect of Transistor Geometry on the Electrical Characteristics of $\mathrm{Si}_{1-x} \mathrm{Ge}_{x}$ Heterojunction Bipolar Transistors at Low Temperatures
}

\author{
M.D.R. Hashim, R.F. Lever, P. Ashburn and G.J. Parker \\ Department of Electronics and Computer Science, University of Southampton, Southampton S017 1BJ, \\ U.K.
}

\begin{abstract}
This paper investigates the effect of using an extrinsic implant on the behaviour of SiGe HBTs at low temperatures. The collector current characteristics of SiGe HBTs with different geometries are measured at temperatures from 77 to $300 \mathrm{~K}$. The temperature dependence of the collector current is different for devices with different geometries and this results from base profile broadening in the vicinity of the extrinsic base implant due to point defects. Process and device simulators are used to explain this effect. A method for eliminating this geometry dependence of the collector current is also described.
\end{abstract}

\section{INTRODUCTION}

The incorporation of SiGe heterojunction bipolar transistors (HBTs) into a standard silicon technology requires the use of low thermal budget processing to avoid the relaxation of the strained SiGe and out-diffusion of boron from the base [1]. This latter effect is particularly problematic because it degrades both the current gain and the cut-off frequency of SiGe HBTs [1]. Earlier research [2], [3] has shown that transient enhanced diffusion can exacerbate the problem of boron out-diffusion from the SiGe base when an emitter implant is made into the silicon above the SiGe base to reduce the emitter contact resistance. Interstitial defects generated by the implant dramatically enhance the diffusivity of the boron in the underlying base. Although this problem can be solved by using a polysilicon emitter [4], it raises the question of whether the use of ion implantation should be completely avoided in SiGe HBT process. In this work, the low temperature characteristics of devices are used to show how transient enhanced diffusion, due to an extrinsic base implant influences the device performance.

\section{DEVICE STRUCTURE AND TECHNOLOGY}

The $\mathrm{p}+$ base and $\mathrm{n}^{--}$emitter were grown using LPCVD. The targeted vertical stack consisted of a $250 \AA$ thick, $2 \times 10^{19} \mathrm{~cm}^{-3}$ boron doped $\mathrm{Si}_{0.84} \mathrm{Ge}_{0.16}$ base followed by a $1500 \AA$ thick, $1 \times 10^{18} \mathrm{~cm}^{-3}$ arsenic doped silicon emitter. Undoped SiGe spacer layers with equal thickness of either $150 \AA$ or $50 \AA$ were introduced on both sides of the base. The thicker undoped spacers are expected to contain the boron out-diffusion in the SiGe during device processing. The structure had a polysilicon emitter contact, formed by implanting $10^{16} \mathrm{~cm}^{-2}, 40 \mathrm{keV}$ As into a $2000 \hat{\AA}$ thick polysilicon layer. Contact to the base was made using a $\mathrm{p}^{+}$extrinsic base, formed by successive implants of $2 \times 10^{15} \mathrm{~cm}^{-2}, 120 \mathrm{keV} \mathrm{B}$ and $2 \times 10^{15} \mathrm{~cm}^{-2}, 35 \mathrm{keV} \mathrm{BF}_{2}$ into the low doped silicon emitter. The thermal budget used in this process was a rapid thermal anneal at $900^{\circ} \mathrm{C}$ for 30 seconds. In this work, four devices are investigated, as summarised in table 1.The basewidths and Ge\% were extracted from SIMS profiles and the mean base doping concentrations estimated from the measured intrinsic base sheet resistance. 
Table 1: Summary of the device information

\begin{tabular}{|c|c|c|c|c|c|c|c|}
\hline $\begin{array}{c}\text { Device } \\
\text { type }\end{array}$ & Ge\% & $\begin{array}{c}\text { Base doping } \\
\left(\mathrm{cm}^{-3}\right)\end{array}$ & $\begin{array}{c}\text { Spacer } \\
(\mathrm{nm})\end{array}$ & $\begin{array}{c}W_{B} \\
(\mathrm{~nm})\end{array}$ & $\begin{array}{c}\mathrm{R}_{B} \\
(\mathrm{k} \Omega / \square)\end{array}$ & $\begin{array}{c}\text { Emitter area } \\
\left(\mu \mathrm{m}^{2}\right)\end{array}$ & $\begin{array}{c}\text { Perimeter } \\
(\mu \mathrm{m})\end{array}$ \\
\hline T1 & 16 & $5 \times 10^{18}$ & 5 & 68 & $1.91 \pm 0.01$ & $4356(66 \times 66)$ & 264 \\
\hline T2 & 16 & $5 \times 10^{18}$ & 5 & 68 & $1.91 \pm 0.01$ & $4356(22 \times 22 \times 9)$ & 792 \\
\hline T3 & 16 & $6 \times 10^{18}$ & 15 & 68 & $2.04 \pm 0.01$ & $4356(66 \times 66)$ & 264 \\
\hline T4 & 16 & $6 \times 10^{18}$ & 15 & 68 & $2.04 \pm 0.01$ & $4356(22 \times 22 \times 9)$ & 792 \\
\hline
\end{tabular}

\section{ANALYSIS PROCEDURE}

For an npn SiGe heterojunction transistor, the temperature dependence of the collector current density is given by [5]:

$$
J_{C}(\mathrm{~T})=\frac{k T \mu_{n}(\mathrm{~T}) n_{i o(\mathrm{Si} G \in)}^{2}(\mathrm{~T})}{N_{A B}(\mathrm{~T}) W_{B}(\mathrm{~T})} \exp \frac{q V_{B E}}{k T} \exp \frac{\Delta E_{G B}}{k T}
$$

where $k$ is Boltzmann's constant, T the temperature, $\mu_{n}(\mathrm{~T})$ the minority carrier electron mobility in the base $[6,7], n_{i o(\operatorname{SiGe})}(\mathrm{T})$ the intrinsic concentration for undoped $\mathrm{SiGe}, W_{B}(\mathrm{~T})$ the neutral basewidth, $N_{A B}(\mathrm{~T})$ the ionized doping concentration in the base, $V_{B E}$ the base/emitter voltage and $\Delta E_{G B}$ the apparent bandgap narrowing (doping-induced) in the base.

The ionized base doping concentration $N_{A B}(\mathrm{~T})$ is related to the measured intrinsic base sheet resistance $R_{B}(\mathrm{~T})$ by:

$$
R_{B}(\mathrm{~T})=\frac{1}{q \mu_{p}(\mathrm{~T}) N_{A B}(\mathrm{~T}) W_{B}(\mathrm{~T})}
$$

where $\mu_{p}(\mathrm{~T})$ is the majority carrier hole mobility in the base $[6,7]$. This equation can be used to calculate the ionized doping concentration in the base $N_{A B}(T)$, assuming that the majority carrier mobility and the basewidth are known.

The temperature dependence of the intrinsic carrier concentration in equation 1 can be expressed as:

$$
n_{i \circ(\operatorname{Si} G)}^{2}(\mathrm{~T})=n_{i o}^{2}(\mathrm{~T}) \exp \frac{\Delta E_{g}}{k T}
$$

where $n_{i o}^{2}(\mathrm{~T})$ is the temperature dependence of the intrinsic carrier concentration in Si which is given by $[8]$ :

$$
n_{i_{o}}^{2}(\mathrm{~T})=4\left(\frac{2 \pi k T}{h^{2}}\right)^{3}\left(r_{n} n_{p}\right)^{1.5} \exp \frac{-E_{G}(\mathrm{~T})}{k T}
$$

where $h$ is Planck's constant, $m_{m}$ and $m_{p}$ the effective masses for electrons and holes [9], $E_{G}(\mathrm{~T})$ the undoped silicon bandgap, which varies with temperature. $\Delta E_{g}$ in equation 3 is the bandgap narrowing in the base due to the presence of the $\mathrm{Ge}$ in the base. For simplicity, in this analysis the effective masses for electrons and holes are assumed to be the same as those in Si.

Combining equations 1 to 4 gives an equation for the temperature dependence of the collector current of a SiGe HBT:

$$
J_{C}(\mathrm{~T})=J_{o}(\mathrm{~T}) \exp \frac{\Delta E_{G B}}{k T} \exp \frac{\Delta E_{g}}{k T}
$$

where the pre-exponential term $J_{0}$ is given by:

$$
J_{\nu}(\mathrm{T})=4 q\left(\frac{2 \pi}{h^{2}}\right)^{3}\left(m_{n} m_{p}\right)^{1.5}(k T)^{4} \mu_{n}(\mathrm{~T}) \mu_{p}(\mathrm{~T}) R_{B}(\mathrm{~T}) \exp \frac{q V_{B E}-E_{G}(\mathrm{~T})}{k T}
$$

The value of the bandgap narrowing in the base can then be obtained from the slope of the graph of:

$$
\ln \left(\frac{J_{C}(\mathrm{~T})}{J_{0}(\mathrm{~T})}\right) \text { versus } 1 / \mathrm{T}
$$


which then yields a value for $\left(\Delta E_{G B}+\Delta E_{g}\right)$. It should be noted that using the above analysis, the intercept of the graph obtained by plotting equation 7 should be equal to unity. If we assumed values for constants in equation 6 are incorrect, for example, the values of effective mass, a value of intercept other than unity would be expected.

\section{RESULTS AND DISCUSSION}

Fig. 1 shows Gummel plots for two $\mathrm{Si} / \mathrm{Si}_{0.84} \mathrm{Ge}_{0.16}$ HBTs with $5 \mathrm{~nm}$ undoped SiGe spacers, measured at 290 and $135 \mathrm{~K}$ with $V_{C B}=0 \mathrm{~V}$. The devices have the same emitter/base area but the perimeters differ by a factor of 3 . The collector current for the device with the shorter perimeter is higher than that of device with the longer perimeter by a factor of approximately 3 at $390 \mathrm{~K}$ and a factor of 40 at 135K. Fig. 2 shows a plot of equation 7 for the two devices over the temperature range of 100 to $315 \mathrm{~K}$. The device with the short perimeter has a higher activation energy $(146 \mathrm{meV})$ than the device with the long perimeter $(101 \mathrm{meV})$ which implies a difference in bandgap narrowing in the base. The reduced collector current in Fig. 1 and the reduced activation energy in Fig. 2 for the device with long perimeter suggest the presence of boron out-diffusion in the base around the perimeter of the emitter. The out-diffusion gives rise to potential barriers at the $\mathrm{E} / \mathrm{B}$ and $\mathrm{C} / \mathrm{B}$ junctions which degrade the collector current.

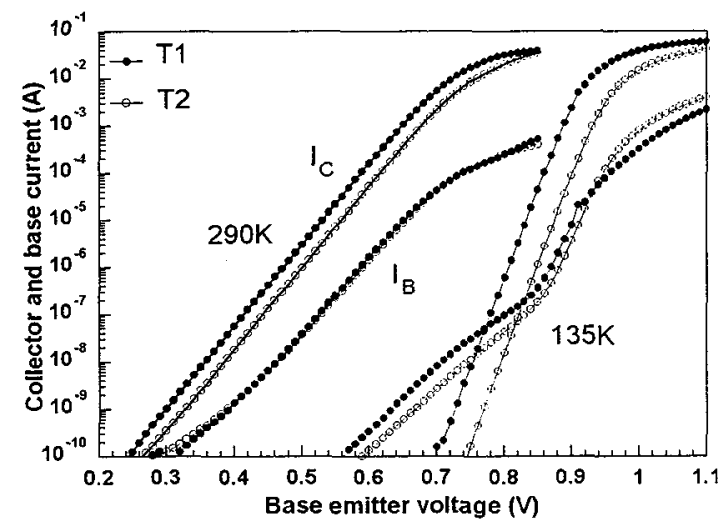

Figure 1: Gummel plots for SiGe HBTs with $5 \mathrm{~nm}$ base spacers at $290 \mathrm{~K}$ and $135 \mathrm{~K}$.

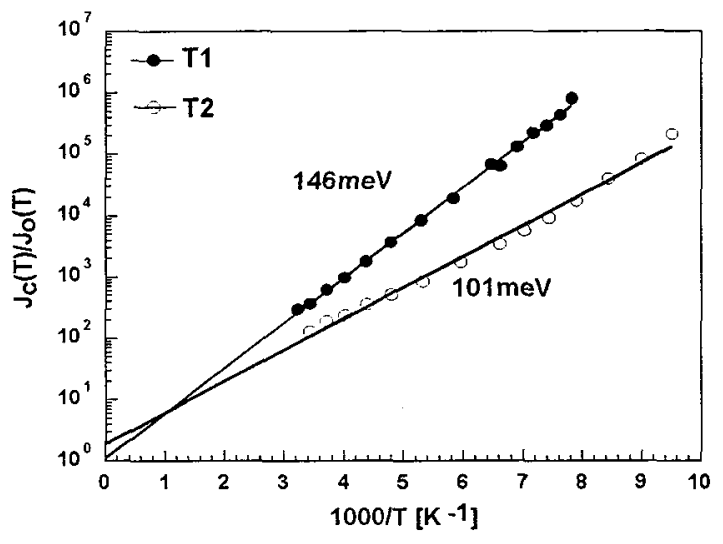

Figure 2: Temperature dependence of the collector current for HBTs with $5 \mathrm{~mm}$ base spacers operating at $V C B=0 \mathrm{~V}$.

To test for the presence of a potential barrier at the $C / B$ junction, the devices were operated with an increased $\mathrm{C} / \mathrm{B}$ reverse bias of $\mathrm{V}_{C B}=5 \mathrm{~V}$ in order to widen the depletion layer and hence reduce the height of the potential barrier. Fig. 3 shows the temperature dependence of the collector current for an increased $\mathrm{C} / \mathrm{B}$ reverse bias of $\mathrm{V}_{C B}=5 \mathrm{~V}$. In comparison with Fig. 2, the activation energies in this figure are higher. This confirms the presence of a parasitic energy barrier at the $B / C$ junction due to boron out-diffusion. It is suspected that the out-diffusion occurs due to transient enhanced diffusion resulting from point defects generated by the p+ extrinsic base implant, as illustrated schematically in the device cross section in Fig. 4.

To confirm this hypothesis, the process simulator TSUPREM-IV was used to estimate the lateral and vertical extent of the boron diffusion adjacent to the $\mathrm{p}+$ extrinsic base contact. The process simulations were performed using the diffusion the parameters for silicon due to the absence of models for SiGe in the simulator. The process simulator was calibrated using the results of TED of boron in silicon of Michel [10]. Fig. 5 shows a plot of the basewidth obtained from the boron output profile of the process simulator against the distance from the $p+$ base contact. It can be seen from this figure that the broadening of the boron profile takes place for distances up to $14 \mu \mathrm{m}$ from 
the implanted area. This boron profile was then inserted into the device simulator MEDICI. In the device simulation, the 3D cylindrical mode was choosen in order to take into account the different base doping profiles across the horizontal base. In this mode the $x$-axis represented the radius of the device emitter/base area and the $y$-axis the length of the cylinder. Also in this device simulation, the germanium profile was assumed to be constant both vertically and horizontally. Simulations were carried out on two devices with the same area $\left(3217 \mu \mathrm{m}^{2}\right)$, but different perimeters. The short perimeter device had a cylindrical geometry, with radius of $32 \mu \mathrm{m}$, and the long perimeter device comprised 10 cylinders connected in parallel, each with a radius of $10 \mu \mathrm{m}$. All the device simulations were performed assuming the dependence of boron profile with distance from the base contact as shown Fig 5. This is consistent with the assumption that the boron profile broadening is the same in all devices due to the identical process steps and subsequent anneal treatment. In the simulations the parameter values described in section 2 were used and the bandgap narrowing due to the presence of Ge was modelled using the data of Iyer et al [11].

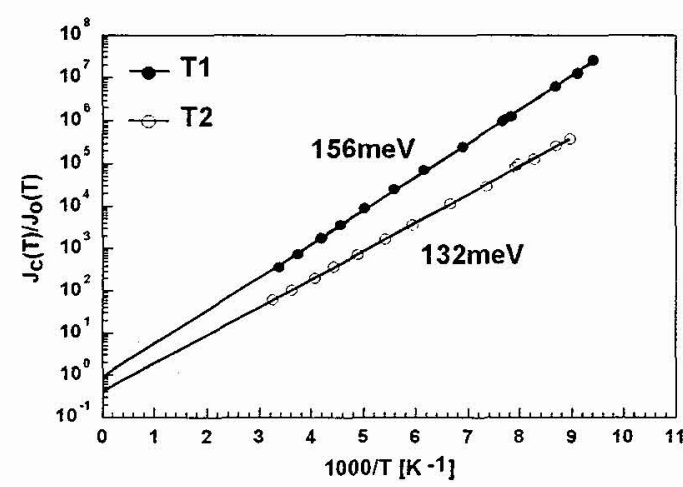

Figure 3: Temperature dependence of the collector current for HBTs with $5 \mathrm{~nm}$ base spacers operating at $\mathrm{VCB}=5 \mathrm{~V}$.

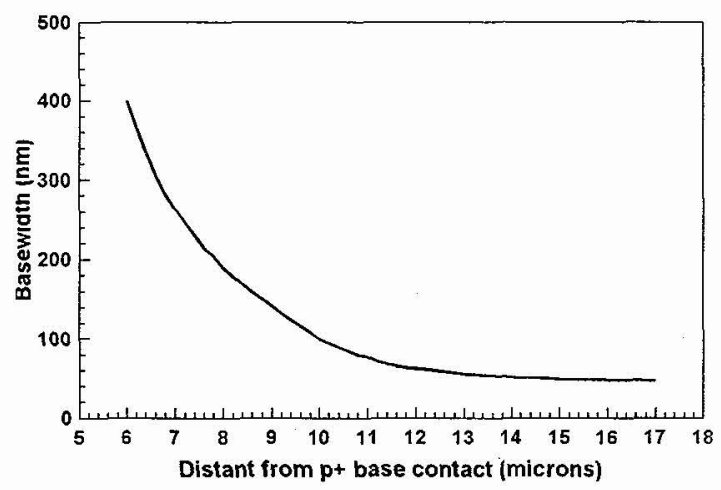

Figure 5: Simulated basewidths against the distance from the $\mathrm{p}+$ base contact.

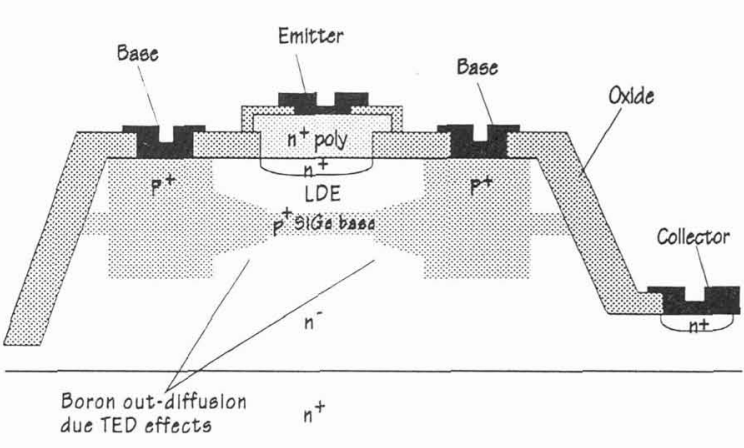

Figure 4: Device cross-section showing the boron outdiffusion due to transient enhanced diffusion (TED) (not to scale).

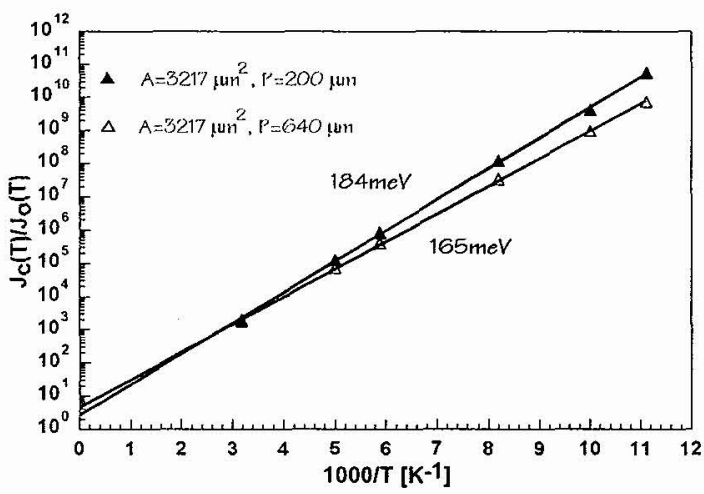

Figure 6: Simmlated temperature dependence of collector current for devices with the same area and different perimeters.

Fig. 6 shows the simulated temperature dependence of the collector current for two devices with the same area but different perimeters. It can be seen that the device with a short perimeter (filled triangles) has a higher activation energy $(184 \mathrm{meV})$ than that the device with a long perime- 
ter $(165 \mathrm{meV})$. These results suggest that point defects from the extrinsic base implant are able to migrate across the entire emitter area of long perimeter device. However in the short perimeter device the point defects are unable to migrate as far as the centre of the intrinsic base, and hence enhanced boron out-diffusion is only obtained around the perimeter of the emitter. The low temperature analysis used in this work provides an average activation energy across the emitter/base area, which qualitatively explains the lower activation energy in devices with a long perimeter. These results however are not totally conclusive since Si diffision parameters were used in the process simulations to model the $\mathrm{SiGe}$ base layer. It would be expected that the out-diffusion would be less severe if the correct diffusion parameters were used, since the diffusion coefficient of boron in $\mathrm{SiGe}$ is lower than that in Si. Further work is therefore being carried out to correctly model the boron profile broadening in the SiGe base layers.

To investigate whether it is possible to eliminate this geometry dependence of the collector current, devices were fabricated with thicker undoped SiGe spacers (15nm). Fig. 7 shows the temperature dependence of the collector current for two comparable $\mathrm{Si} / \mathrm{Si}_{0.84} \mathrm{Ge}_{0.16}$ HBTs with the same emitter/base area and different perimeter lengths. Again the measurements were made with $\mathrm{V}_{C B}=0 \mathrm{~V}$. A slope of $157 \mathrm{meV}$ is obtained for the device with the shor't perimeter (T3) and $150 \mathrm{meV}$ for the device with the long perimeter. Compared with Fig. 2 it can be seen that the activation energies are approximately the same, suggesting that the geometry dependency of the collector current has been reduced dramatically, if not completely eliminated. On the application of a $5 \mathrm{~V}$ reverse bias to reduce any residual potential barrier at the collector/base junction, these slopes increase to $159 \mathrm{meV}$ and $156 \mathrm{meV}$ respectively as shown in Fig. 8.
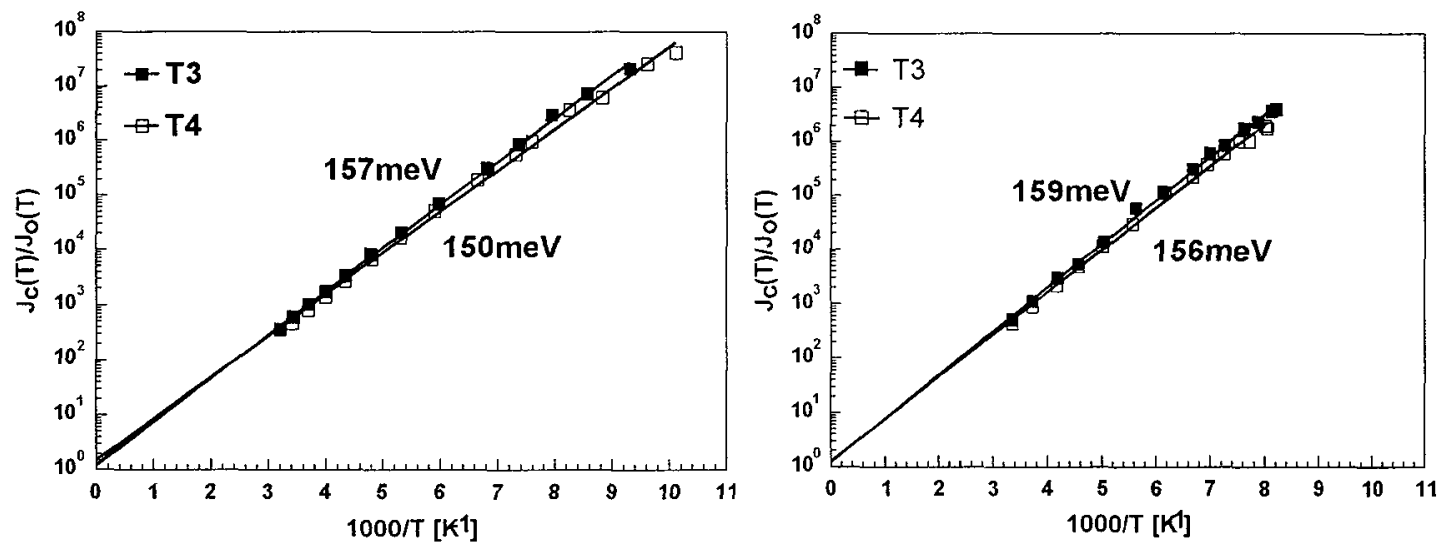

Figure 7: Temperature dependence of collector current for devices with $15 \mathrm{~nm}$ base spacers operatiıg at $\mathrm{VCB}=0 \mathrm{~V}$.
Figure 8: Temperature dependence of collector curreny for devices with $1511 \mathrm{~m}$ base spacers operating at $V C B=-5 \mathrm{~V}$.

It can be concluded that increasing the base spacer thickness to $15 \mathrm{~nm}$ has eliminated the majority of the parasitic energy barrier at the collector/base junction around the perimeter. This can be seen by comparing the slope of $132 \mathrm{meV}$ (T2) in Fig. 3 with that of $150 \mathrm{meV}$ (T4) in Fig. 7. However a small residual energy barrier may still be present, even for a spacer thickness of $15 \mathrm{~nm}$, as can be seen from the increase of the slope from $150 \mathrm{meV}$ in Fig. 7 to $156 \mathrm{meV}$ in Fig. 8 on the application of a reverse collector bias. This suggests that a careful choice of undoped SiGe spacer thickness must be made when an ion implanted extrinsic base is incorporated into a SiGe HBT process. The low temperature analysis technique used in this work is highly sensitive and is an ideal technique for studying small amounts of boron out-diffision from the base of a SiGe HBT.

\section{Acknowledgements}

M D R Hashim would like to particularly acknowledge the financial support of the Universiti Sains Malaysia which enabled him to carry out this work. 


\section{References}

[1]. Slotboom J W et al., IEEE Electron. Device Let.., 12 (1991) 486.

[2]. Pruijmboom A et al., IEEE Electron Device Lell.., 12 (1991) 357.

[3]. Pruijmboom A et al., Microelectron. Eng., 19 (1992) 427.

4]. Crabbe E F et al., IEEE Electron. Device Lett.. 14 (1993) 478.

[5]. Ashburn P A et al., IEEE Trans Electron Device, May (1996) in press.

6]. Klaassen D B M, Solid State Electronics, 35 (1992) 953.

7]. Klaassen D B M, Solid State Electronics, 35 (1992) 961.

[8]. Sze S M, Physics of Semiconductor Devices, (2nd. Ed., Wiley NY, 1981) p19.

[9]. Green M A, Jpn. Jnl. Appl Phys., 67 (1990) 2944-2953.

[10]. Michel A E., Appl. Phys. Lett., 50 (1987) 416-418.

[11]. Iyer S S et al, IEEE Trans. Electron Devices, 36 (1989) 2043. 